\title{
3 Research Square

\section{Sustainable environment, energy and finance in China: Evidence from dynamic modelling using carbon emissions and ecological footprints}

\section{Rizwan Ali}

The University of Lahore Lahore Business School

Mubeen Abdur Rehman ( $\sim$ mubeenurehman@gmail.com )

University of Lahore - Raiwind Road Campus: The University of Lahore https://orcid.org/0000-00019007-9880

\section{Ramiz ur Rehman}

The University of Lahore Lahore Business School

\section{Collins G. Ntim}

Southampton New College: University of Southampton

\section{Research Article}

Keywords: Sustainable environment, energy and finance, market capitalization, Carbon/CO2 emissions, ecological footprints, DARDL, China

Posted Date: March 3rd, 2022

DOI: https://doi.org/10.21203/rs.3.rs-1308531/v1

License: (c) (i) This work is licensed under a Creative Commons Attribution 4.0 International License. 
1 TITLE: Sustainable environment, energy and finance in China: Evidence from dynamic

2 modelling using carbon emissions and ecological footprints

3

4 AUTHOR DETAILS:

5 Author 1

6 Dr. Rizwan Ali

7 Assistant Professor of Finance

8 Lahore Business School, The University of Lahore, Lahore, Pakistan

$9 \quad$ Author 2

10 Mr. Mubeen Abdur Rehman

11 PhD Scholar,

12 Lahore Business School, The University of Lahore, Lahore, Pakistan

13 Author 3

14 Dr. Ramiz ur Rehman

$15 \quad{ }^{1}$ Faculty of Business, Sohar University, Oman

$16 \quad{ }^{2}$ Associate Professor of Finance

17 Lahore Business School, The University of Lahore, Lahore, Pakistan

18 Author 4

19 Dr. Collins G. Ntim

20 Professor of Accounting

21 Southampton Business School, University of Southampton, UK

22 Corresponding author: Mubeen Abdur Rehman

23 [Corresponding Author's Email]: mubeenurehman@gmail.com

24 


\section{Highlights:}

28

29

30

31

32

34

35

36

37

38

39

40

41

42

43

44
- Robust results explained that sustainable finance place a lucrative cause to preserve the environment

- A novel Dynamic Autoregressive Distributed Lag technique is applied

- For this study, annual data is collected for China over 1970-2017

- In the long run, sustainable economic factors show a positive impact on carbon emissions whereas economic growth, energy consumption, and exports improve the ecosystem

- On contrary, in the short run, urbanization supports the environment while economic development, energy use, and exports exert a positive impact on the environment 
Sustainable environment, energy and finance in China: Evidence from dynamic modelling using carbon emissions and ecological footprints

\section{Abstract}

This study investigates sustainable finance along with sustainable economic factors on both carbon

49 emissions and ecological footprints in China. A novel Dynamic Autoregressive Distributed Lag

50 technique is applied, results revealed sustainable finance exerts positive/negative influence on

51 carbon emissions in the long- and short-run, respectively. Results are robust with ecological

52 footprints that sustainable finance placed a lucrative cause to preserve the environment.

53 Sustainable economic factors show a positive impact on carbon emissions in the long run, while

54 economic growth, energy consumption, and exports improve environmental quality. Conversely,

55 in the short run, urbanization supports the environment while economic development, energy use,

56 and exports exert a positive impact. In addition, this study suggests useful policy implications for

57 the stakeholders.

Keywords: Sustainable environment, energy and finance, market capitalization, Carbon/CO2 59 emissions, ecological footprints, DARDL, China.

\section{Introduction}

61 Environmental degradation is a foremost challenge for both developed and developing economies

62 across the world. In particular, the crucial question facing businesses, environmental activists,

63 academics, governments, managers, policy-makers and regulators is how to cut greenhouse gases

$64(\mathrm{GHG}) /$ carbon/ $\mathrm{CO}_{2}$ emissions and ecological footprints (sustainable environment/energy), while

65 generating wealth (sustainable finance) for society. Answering this crucial policy question and 
preserving the environment is arguably the most demanding task for the current human generation

67 (Collins and Zheng 2015; Bekun et al., 2019a 2019b).

68 Environmental degradation is triggered by a flood, fire, and the most prominently, GHG emissions.

69 These events can disrupt the natural resources, infrastructure, agricultural land, and the most

70 importantly, human lives. Within the context of the obligations imposed by the Paris Agreement

71 in 2015, these have major implications, especially in emerging economies. Meanwhile, China as

72 the largest emerging economy is the leading energy consumer and the first $\mathrm{CO}_{2}$ emitter in the

73 world (Lahiani 2020). For example, China's carbon emissions have increased from 0.94 in 1970

74 to 7.18 metric tons per capita in 2016, which represents almost seven times in growth terms over

75 the same period (World Bank 2018). In this regard, it is essential to sustain economic and financial

76 growth, whilst maintaining a sustainable environment by curtailing $\mathrm{CO}_{2} / \mathrm{GHG}$ emissions. In this

77 study, we contend that the answer to the questions mentioned above is committing to sustainable

78 finance through managing stock market capitalization. The purpose of this study, therefore, is to

79 investigate the influence of sustainable finance (market capitalization) and economy on

80 environmental degradation with the help of carbon emissions and ecological footprints over 38

81 years in China. In addition, other sustainable economic factors, such as energy use, economic

82 growth, exports, non-renewable energy use, and urbanization are taken as extra predictors in this

83 research.

84 Apart from carbon emissions, ecological footprints have been proposed by Rees (1992) as a 85 cumulative factor for environmental quality (Charfeddine 2017; Fakher 2019; Destek and Sinha 86 2020). Moreover, it is indicated that these were the consequences of financial and non-financial 87 activities (Nathaniel and Khan 2020). Generally, the ecological footprint shows a part of the water 
and land, which is claimed to be used by the operators to manufacture products for consumption and to produce waste continually (Wackernagel and Rees 1997). Similarly, China is considered the leading country in ecological footprints in the world (Ulucak and Lin 2017). Sustainable

91 finance i.e., market capitalization is a decent indicator of the size of firms and is corroborated by

92 the finance literature. It contains additional elements for which the balance sheet is silent, such as 93 company reputation, growth, and management expertise (Adom et al. 2020). Bougatef (2017) 94 claimed that market capitalization is a way through which profitability can be enhanced. Fig 1 95 represents the line graphs of $\mathrm{CO}_{2}$ emissions (metric tons per capita) and ecological consumption 96 per capita (total) in China from 1970 to 2017. It is evident from both graphs that environmental 97 degradation is progressively increasing that making China the world largest $\mathrm{CO}_{2}$ emitter country 98 in the world. The point emanated from the figure that environmental pollution is continually 99 increasing and need to be declined for a healthier future.

100 To the best of our understanding, this research is unique to explore the role of sustainable finance 101 by examining the effect of market capitalization on the environment through $\mathrm{CO}_{2}$ emissions and 102 ecological footprints. Thus, based on the review of prior research related to financial indicators 103 and the environment, this study contributes to environmental finance literature in a number of 104 ways. First and foremost, a plethora of research in Environmental Kuznets Curve EKC perspective 105 has been done on environmental degradation with financial development (Nosheen et al. 2019; 106 Lahiani 2020; Rahman et al. 2020), economic growth (Lau et al. 2014; Acquaye et al. 2017; Dogan 107 et al. 2019; Khan et al. 2019; Lahiani 2020), energy consumption (Bölük and Mert 2014; Wang et 108 al. 2016a; Bhattacharya et al. 2017; Sarkodie and Strezov 2019), non-renewable energy 109 consumption (Bhattacharya et al. 2017; Dogan et al. 2019; Sarkodie and Strezov 2019) and 110 urbanization (Zhang and Lin 2012; Erdoğan 2013), but the literature is silent to uncover the 
111 sustainable finance considering the rapid increases in the market capitalization of listed companies

112 in emerging economies.

\section{[INSERT FIGURE 1]}

114 Fig 2 indicates the ecological footprints consumption per person for China from 1960 to 2017. The

115 value of ecological footprints consumption global hectares per person was initially favourable in

1161960 and it became adverse in 1969. The value of ecological footprints consumption increased and

117 reached from 1 to 2 global hectares per person in 33 years. Then, it increased exponentially and

118 crossed the next unit in just six years. Therefore, ecological footprint consumption in China

119 continues to grow. The reason behind this is twofold. Firstly, China is the largest populated country

120 globally, and this massive population demands more natural resources. Secondly, China is the

121 largest manufacture and exporter globally.

122 To the best of our understanding, this research is unique to explore the role of sustainable finance

123 by examining the effect of market capitalization on the environment through $\mathrm{CO}_{2}$ emissions and

124 ecological footprints. Thus, based on the review of prior research related to financial indicators

125 and the environment, this study contributes to environmental finance literature in a number of

126 ways. First and foremost, a plethora of research in Environmental Kuznets Curve EKC perspective

127 has been done on environmental degradation with financial development (Nosheen et al. 2019;

128 Lahiani 2020; Rahman et al. 2020), economic growth (Lau et al. 2014; Acquaye et al. 2017; Dogan

129 et al. 2019; Khan et al. 2019; Lahiani 2020), energy consumption (Bölük and Mert 2014; Wang et

130 al. 2016a; Bhattacharya et al. 2017; Sarkodie and Strezov 2019), non-renewable energy

131 consumption (Bhattacharya et al. 2017; Dogan et al. 2019; Sarkodie and Strezov 2019) and

132 urbanization (Zhang and Lin 2012; Erdoğan 2013), but the literature is silent to uncover the 
133 sustainable finance considering the rapid increases in the market capitalization of listed companies

134 in emerging economies.

\section{[INSERT FIGURE 2]}

136 Secondly, the existing research enormously utilized autoregressive distributive lag (ARDL)

137 (Pesaran et al. 1999; Pesaran et al. 2001), Non-linear ARDL (NARDL) (Shin et al. 2014) and 138 Quantile ARDL (QARDL) (Cho et al. 2015), while in this study we have applied novel Dynamic 139 ARDL (DARDL) simulations to consider the effects of long and short run association of among 140 the variables that we investigate. DARDL model is robust to automatically plot positive and 141 negative simulations (Jordan and Philips 2018). Thirdly, the study is exclusive in examining the 142 influence of sustainable finance using market capitalization and sustainable economic factors with 143 energy consumption, economic growth, urbanization, and exports on GHG emissions to validate 144 EKC and additionally, ecological footprints in order to obtain robust results. Lastly, this research 145 contributes to the Chinese Economy perspective, which is the leading manufacturer globally and 146 hence, exporting products around the globe. It necessarily seeks to consume traditional energy 147 sources based on fossil fuels (Lahiani 2020). In doing so, this study investigates the relationships 148 among sustainable environment, finance and energy by applying dynamic modelling using carbon 149 omission and ecological footprints.

150 The remainder of the study is structured as follows. Section 2 presents the literature review, while 151 Section 3 outlines the methodology. Furthermore, Section 4 reports and interprets the findings 152 whilst Section 5 concludes the paper including outlining the policy implications. 


\section{Literature review}

155 Countries' economic performance depends on energy, but the excessive usage of traditional 156 sources of energy may result in global warming (Apergis and Garćia 2019). Energy use and the

157 environment have a significant relationship, and the results suggested that more use of 158 nonrenewable energy plays a key role in the deterioration of the environment (Katircioğlu and 159 Taşpinar 2017; Baloch et al. 2019). In addition, the excessive use of traditional energy leads to 160 environmental and ecological degradation in both developing and developed nations (Ahmed et 161 al. 2020). Zhang et al. (2017) reported that utilization of sustainable energy improves 162 environmental conditions, whereas non-renewable energy consumption deteriorates the 163 environment. Renewable energy and energy efficiency play their role in mitigating the GHG 164 emissions in BRICS countries (Akram et al., 2020). Economic complexity and non-renewable 165 energy consumption cause detriment to the ecological footprints (Shahzad et al. 2021).

166 Literature shows a positive influence of sustainable economic factors such as economic growth on 167 GHG emissions in developing economies. For instance, Nazir et al. (2018) examined that per 168 capita income is positively significant with carbon emissions in Kyoto Annex countries. As the 169 economic growth of an economy increases, environmental pollution also increases (Katircioğlu 170 and Taşpinar 2017; Dogan et al. 2019; Rahman et al. 2002. The relationship between carbon 171 emissions and economic growth was analyzed using the NARDL model in China. The examined 172 results of asymmetric relationship showed that positive and negative change in GDP brings 173 significantly positive and negative impacts on the environment, respectively (Lahiani 2020). In 174 addition, Fareed et al. (2018) analyzed the association between tourism, economic growth, and 175 terrorism. The results showed statistically significant and asymmetric behaviour. The impact of 
176 non-renewable energy and economic growth is positive on ecological footprints. Non-sustainable

177 economic growth holds a significant direct effect on the surge in ecological footprints (Sharif et

178 al. 2020).

179 Zhang et al. (2017) reported that renewable and non-renewable energy use with carbon emissions.

180 The outcomes are evident that sustainable energy impedes environmental degradation, whereas

181 non-sustainable energy consumption deteriorates the environment. The relationship among

182 renewable energy use, GDP, and carbon emissions are asymmetric in both the long and short-run

183 in Saudi Arabia (Toumi and Toumi 2019). Similarly, the outcomes of non-sustainable energy

184 consumption and economic growth embrace a statistically significant impact on ecological

185 footprints (Sharif et al., 2020). Dogan et al. (2019) examined the influence of non-renewable 186 energy use on $\mathrm{CO}_{2}$ emissions, while Sharif et al. (2020) on ecological footprint, and both the

187 studies revealed that the consumption of non-sustainable energy leads to the degradation of the 188 environment.

189 Hashmi et al. (2020) studied the influence of urbanization on $\mathrm{CO}_{2}$ emissions. They found that 190 urban agglomeration has a direct and significant effect on environmental degradation in the top 191 ten urban agglomerated countries. Urbanization holds a positively significant impact on the 192 ecological footprints (Godil et al. 2021). Similarly, Sadorsky (2010) reported that urbanization has 193 a significant positive effect on $\mathrm{CO}_{2}$ emissions in panel data of emerging economics. The 194 association of urbanization and carbon emissions is significant, leading to the deterioration of the 195 environment (Pata 2018; Dogan et al. 2019).

196 Mahmood et al. (2019) analyzed the nonlinear or asymmetric impact of trade on carbon emissions. 197 The results have shown that the immediate change in trade significantly augments $\mathrm{CO}_{2}$ emissions, 
while the negative change improves the environment. In addition, there is a nonlinear impression of FDI and trade on $\mathrm{CO}_{2}$ emissions in Turkey (Haug and Ucal 2019). Godil et al. 2021 analyzed the influence of financial development and transportation on ecological footprints using Quantile ARDL. The outcomes of the study revealed that both transportation and financial development present reasons to preserve the environment. In the above-mentioned literature, it is evident that a lot of work has been done to explore the sustainable environment $\left(\mathrm{CO}_{2}\right.$ emissions or ecological footprints) with financial indicators (financial development and economic growth) and nonfinancial indicators (transportation, energy consumption, and urbanization). In contrast, the literature is silent to uncover the impact of sustainable finance on the environment.

\section{Methodology}

For this study, annual data is collected for China over 1970-2017. The description of the variables is presented in Table 1. Moreover, data for carbon dioxide emissions $\left(\mathrm{CO}_{2}\right)$, economic growth (GDP), energy use (EC), exports of products (EXP), the market capitalization of listed companies (MCAP), and urban population (URB) is collected from World Bank (World Development Indicators). In contrast, data of ecological footprints (EF) and non-renewable energy (NREC) are gathered from Global Footprint Network (GFPN) and BP Statistics, respectively.

For the selection of variables, this research follows the prior studies. The relationship of GDP (Katircioğlu and Taşpinar 2017; Pata 2018; Lahiani 2020), energy consumption (Katircioğlu and Taşpinar 2017; Nosheen et al. 2019), non-renewable energy consumption (Dogan et al. 2019), urbanization (Dogan et al. 2019), and trade (Nosheen et al. 2019) is examined with greenhouse gases emissions. Similarly, financial development results and carbon emissions are enormously analyzed (Pata 2018; Eren et al. 2019; Rahman et al. 2020). 
220 In line with existing literature, the variables such as market capitalization, exports, economic

221 growth, energy use, and urbanization are selected to examine their impact on the sustainable

222 environment in China for 48 years, taking from 1970 to 2017 . The model of this study is presented

223 as follows.

$224(\mathbf{C O 2})_{\mathbf{t}}=\beta_{\mathrm{O}}+\beta_{1} \mathrm{MCAP}_{\mathrm{t}}+\beta_{2} \mathrm{GDP}_{\mathrm{t}}+\beta_{3} \mathrm{EC}_{\mathrm{t}}+\beta_{4} \mathrm{NREC}_{\mathrm{t}}+\beta_{5} \mathrm{URB}_{\mathrm{t}}+\beta_{6} \mathrm{EXP}_{\mathrm{t}}+\varepsilon_{\mathrm{t}}$

225 Along with carbon emissions, this study also considered the ecological footprints as another proxy

226 for the environment. Sharif et al. (2020) examined the influence of GDP and energy consumption

227 (renewable and non-renewable) on ecological footprints, while Godil et al. (2021) explored

228 urbanization, transport, and financial development with ecological footprints. Hence, the second

229 model for this study can be as follow.

$230(\mathbf{E F})_{\mathbf{t}}=\beta_{\mathrm{O}}+\beta_{1} \mathrm{MCAP}_{\mathrm{t}}+\beta_{2} \mathrm{GDP}_{\mathrm{t}}+\beta_{3} \mathrm{EC}_{\mathrm{t}}+\beta_{4} \mathrm{NREC}_{\mathrm{t}}+\beta_{5} \mathrm{URB}_{\mathrm{t}}+\beta_{6} \mathrm{EXP}_{\mathrm{t}}+\varepsilon_{\mathrm{t}}$

\subsection{ARDL bound testing}

232 ARDL bounds test results are utilized to demonstrate the long-run association among the study 233 variables, and the value of f-statistics indicate the long-run relationship. If the f-value is higher 234 than the upper limit at a 5\% significance level, then long-term co-integration among variables is 235 assumed (Pesaran et al. 2001). But, if the f-value is smaller than the lower critical limit, then the 236 long-run relationship is absent. If the f-value lies between the lower and upper limit, co-integration 237 is considered un-decidable. The following hypothesis is assumed for checking long-run 238 relationships among variables. 
242 The bounds testing approach equation is presented below.

$243 \Delta \mathbf{C O 2}_{\mathrm{t}}=\mathrm{a}_{0}+\delta_{1} \mathrm{CO}_{\mathrm{t}-\mathrm{i}}+\delta_{2} \mathrm{MCAP}_{\mathrm{t}-\mathrm{i}}+\delta_{3} \mathrm{GDP}_{\mathrm{t}-\mathrm{i}}+\delta_{4} \mathrm{EC}_{\mathrm{t}-\mathrm{i}}+\delta_{5} \mathrm{NREC}_{\mathrm{t}-\mathrm{i}}+\delta_{6} \mathrm{URB}_{\mathrm{t}-\mathrm{i}}$

$$
+\delta_{7} \mathrm{EXP}_{\mathrm{t}-\mathrm{i}}+\sum_{i=1}^{r} \beta_{1} \mathrm{MCAP}_{\mathrm{t}-\mathrm{i}}+\sum_{i=1}^{r} \beta_{2} \mathrm{GDP}_{\mathrm{t}-\mathrm{i}}+\sum_{i=1}^{r} \beta_{3} \mathrm{EC}_{\mathrm{t}-\mathrm{i}}+\sum_{i=1}^{r} \beta_{4} \mathrm{NREC}_{\mathrm{t}-\mathrm{i}}
$$

$$
+\sum_{i=1}^{r} \beta_{5} \mathrm{URB}_{\mathrm{t}-\mathrm{i}}+\sum_{i=1}^{r} \beta_{6} \mathrm{EXP}_{\mathrm{t}-\mathrm{i}}+\varepsilon_{\mathrm{t}}
$$

246

247

248

249 250 footprints.

251

252

253

\section{4}

255

256

257

258

In the equation mentioned above, $\Delta$ shows change operator while $\mathrm{t}-\mathrm{i}$ indicates optimal lag selection based on SBIC and HQIC as shown in Table $4 . \delta_{1}$ to $\delta_{7}$ and $\beta_{1}$ to $\beta_{6}$ are coefficients that will be estimated. In addition to $\mathrm{CO}_{2}$ emissions, ecological footprints are also examined with predictor variables to robust the results. Following is the bound testing approach equation for ecological

$$
\begin{aligned}
\Delta \mathbf{E F}_{\mathrm{t}}=\mathrm{a}_{0}+ & \delta_{1} \mathrm{EF}_{\mathrm{t}-\mathrm{i}}+\delta_{2} \mathrm{MCAP}_{\mathrm{t}-\mathrm{i}}+\delta_{3} \mathrm{GDP}_{\mathrm{t}-\mathrm{i}}+\delta_{4} \mathrm{EC}_{\mathrm{t}-\mathrm{i}}+\delta_{5} \mathrm{NREC}_{\mathrm{t}-\mathrm{i}}+\delta_{6} \mathrm{URB}_{\mathrm{t}-\mathrm{i}} \\
& +\delta_{7} \mathrm{EXP}_{\mathrm{t}-\mathrm{i}}+\sum_{i=1}^{r} \beta_{1} \mathrm{MCAP}_{\mathrm{t}-\mathrm{i}}+\sum_{i=1}^{r} \beta_{2} \mathrm{GDP}_{\mathrm{t}-\mathrm{i}}+\sum_{i=1}^{r} \beta_{3} \mathrm{EC}_{\mathrm{t}-\mathrm{i}}+\sum_{i=1}^{r} \beta_{4} \mathrm{NREC}_{\mathrm{t}-\mathrm{i}} \\
& +\sum_{i=1}^{r} \beta_{5} \mathrm{URB}_{\mathrm{t}-\mathrm{i}}+\sum_{i=1}^{r} \beta_{6} \mathrm{EXP}_{\mathrm{t}-\mathrm{i}}+\varepsilon_{\mathrm{t}}
\end{aligned}
$$

\subsection{Dynamic ARDL simulations}

ARDL model was proposed by (Pesaran et al. 1999; Pesaran et al. 2001). It presents numerous benefits over other co-integration techniques (Duasa 2007). First of all, ARDL can be applied with different lag lengths of the variables as some model demands identical lags (Engle and Granger 1987; Johansen and Juselius 1990). Secondly, this model can be utilized if the data is stationary at 
259 I (0) or I (1) or a combination of both orders. Lastly, the ARDL model is favourable when the 260 sample size is small (Narayan 2004).

261 After developing the ARDL technique, Shin et al. (2014) introduced the NARDL model to satisfy

262 the asymmetric effects among variables. Later on, Cho et al. (2015) enhanced this model and 263 presented the QARDL technique. In addition, Jordan and Philips (2018) proposed Dynamic ARDL 264 with dynamic simulations to consider the effects of the long and short-run association of variables. 265 This newly developed model is competent enough to plot positive and negative simulations 266 automatically. Hence, the following models of this study are proposed for a sustainable 267 environment using dynamic ARDL.

268

269

270

271

272

273

274

275

276

277

278

279

$$
\begin{aligned}
\Delta \mathbf{C O 2}_{\mathbf{t}}=\varphi_{0}+ & \theta_{0} \mathrm{CO}_{\mathrm{t}-1}+\beta_{1} \Delta \mathrm{MCAP}_{\mathrm{t}}+\theta_{1} \mathrm{MCAP}_{\mathrm{t}-1}+\beta_{2} \Delta \mathrm{GDP}_{\mathrm{t}}+\theta_{2} \mathrm{GDP}_{\mathrm{t}-1}+\beta_{3} \Delta \mathrm{EC}_{\mathrm{t}} \\
& +\theta_{3} \mathrm{EC}_{\mathrm{t}-1}+\beta_{4} \Delta \mathrm{NREC}_{\mathrm{t}}+\theta_{4} \mathrm{NREC}_{\mathrm{t}-1}+\beta_{5} \Delta \mathrm{URB}_{\mathrm{t}}+\theta_{5} \mathrm{URB}_{\mathrm{t}-1}+\beta_{6} \Delta \mathrm{EXP}_{\mathrm{t}} \\
& +\theta_{6} \mathrm{EXP}_{\mathrm{t}-1}+\mathrm{YECT}_{\mathrm{t}-1}+\varepsilon_{\mathrm{t}} \\
\mathrm{EEF}_{\mathrm{t}}=\varphi_{0}+ & \theta_{0} \mathrm{CO}_{\mathrm{t}-1}+\beta_{1} \Delta \mathrm{MCAP}_{\mathrm{t}}+\theta_{1} \mathrm{MCAP}_{\mathrm{t}-1}+\beta_{2} \Delta \mathrm{GDP}_{\mathrm{t}}+\theta_{2} \mathrm{GDP}_{\mathrm{t}-1}+\beta_{3} \Delta \mathrm{EC}_{\mathrm{t}} \\
& +\theta_{3} \mathrm{EC}_{\mathrm{t}-1}+\beta_{4} \Delta \mathrm{NREC}_{\mathrm{t}}+\theta_{4} \mathrm{NREC}_{\mathrm{t}-1}+\beta_{5} \Delta \mathrm{URB}_{\mathrm{t}}+\theta_{5} \mathrm{URB}_{\mathrm{t}-1}+\beta_{6} \Delta \mathrm{EXP}_{\mathrm{t}} \\
& +\theta_{6} \mathrm{EXP}_{\mathrm{t}-1}+\mathrm{YECT}_{\mathrm{t}-1}+\varepsilon_{\mathrm{t}}
\end{aligned}
$$

\section{Results and discussion}

Table 2 displays the descriptive statistics of all the variables of this study. Variables have positive mean values, and it is shown that economic growth has the highest mean of 3.0440 , followed by energy consumption, 2.9640. Similarly, GDP is more volatile than the rest of the given variables.

On the other hand, ecological footprints and urbanization have a minimum standard deviation. GDP has a larger range value, which is 1.5070 . Skewness values show that almost all the variables 
280 are moderately skewed because given values lie between $0-0.5$. Kurtosis values are less than 3 , 281 and hence, kurtosis has a somewhat thin tail.

282 Table 3 reveals the unit root tests of study variables using ADF and ZA (Zivot and Andrews 2002)

283 tests. In addition, the structural break is found by using the ZA unit root test, as shown in the table.

284 These tests represent that variables are non-stationary at I (0), whereas all of them become 285 stationary at first difference. Hence, both the unit root tests reject the null hypothesis when applied 286 at I (1), representing the accomplishment of the condition for ARDL (Pesaran et al. 1999; Pesaran 287 et al. 2001). Table 4 shows lag selection indication based on Vector Auto-Regressive (VAR) model 288 (Khan et al. 2019). It presents the results of LR, FPE, AIC, SBIC, and HQIC criteria. As per the 289 SBIC and HQIC, the first lag is appropriate, while AIC indicates that the second lag is satisfactory. 290 Hence, for the model selection, SBIC and HQIC are used with lag one.

\section{[INSERT TABLE 2]}

292 Table 5 describes the ARDL bounds testing outcomes to demonstrate the long-term relationship 293 among variables. F-statistics value is 20.9330 and is greater than the upper limit at $1 \% p$-value 294 (Pesaran et al. 2001). The model has sufficient evidence to accept the alternative hypothesis 295 representing that the variables of this study embrace long-run cointegration and equilibrium. 296 Moreover, the error correction term (ECT) is negative and significant in Table 6 corroborates the 297 cointegration (Kanjilal and Ghosh 2013).

298 Table 6 displays the results of dynamic ARDL simulations. The model outcomes indicate that 299 market capitalization has a significant association with carbon emissions for both the long and 300 short-run. China represents a 4 to $5 \%$ contribution of market capitalization (percentage of GDP) 
301

302

303

304

305

306

307

308

309

310

311

312

313

314

315

316

317 towards the environment. The relationship indicates that market capitalization behaves negatively and positively in the short and long-run. This is because China is an emerging economy, and an increase in market capitalization helps to save the environment. Then, in the long run, this impact becomes adverse and shifts to negative due to more investment and consumption of traditional sources of energy. Hence, China is leading in energy consumption and is the biggest carbon emitter country across the world (Lahiani 2020).

\section{[INSERT TABLE 3]}

\section{[INSERT TABLE 4]}

The outcome of short-run economic growth shows the positive and insignificant influence on $\mathrm{CO}_{2}$ emissions in China. The $1 \%$ increase in GDP influences to increase of $0.26 \%$ in environmental degradation per year. The positive effect of GDP on carbon emission shows that currently, China falls at the first stage of EKC and is moving towards industrial richness. On the other hand, in the long run, economic growth shows a negative impact on $\mathrm{CO}_{2}$ emission in China because there will be a threshold point when $\mathrm{CO}_{2}$ emissions would start to decline even though GDP per capita is increasing (Grossman and Krueger 1991). These outcomes are consistent with the literature, which explains that economic growth might lead to environmental degradation (Sharma 2011; Acquaye et al. 2017; Pata 2018; Dogan et al. 2019; Lahiani 2020).

The results of dynamic ARDL simulations report a direct and significant association between energy use and carbon emissions in the short run. China is an emerging economy and the largest producer of manufactured goods in the world. Hence, an increase of $1 \%$ in energy use pollutes the environment by $0.51 \%$ due to more traditional energy sources in the short run. On the other hand, 
322 this relationship shifts and becomes negatively insignificant in the long run. The coefficient is also

323 decreased from 0.51 to 0.28 in the long run, which indicates that China tends towards more

324 renewable energy use (Shahbaz et al. 2013; Wang et al. 2016a; Bhattacharya et al. 2017; Sarkodie

325 and Strezov 2019). It is indicated that emerging countries of the world are impatient for economic

326 growth. These economies use traditional ways of energy sources based on fossil fuels and hence,

327 causing the quality of the environment (Khan et al. 2019).

\section{[INSERT TABLE 5]}

329 The results of Table 6 show that between non-renewable energy use and GHG emissions, there exists a significantly positive and negative association in the short and long-run, respectively, in

331 China. This is due to the long-lasting effect of non-renewable energy use on the environment.

332 Findings of urbanization represent insignificant relation with carbon emissions. This relationship

333 is direct in the long-run whereas inverse in the long-run. The coefficient shows that urbanization

334 is more robust in the long-run than in the long-run in China. Wang et al. (2016b) studied the

335 association of energy use and urbanization with $\mathrm{CO}_{2}$ emissions, and the outcomes of the study

336 presented that urbanization is a key indicator of environmental degradation. There exists a direct

337 impact of urbanization on GHG emissions (Zhang and Lin 2012; Erdoğan 2013). The outcomes of

338 urbanization are similar to (Pata 2018; Dogan et al. 2019) but opposite to (Khan et al. 2019).

339 The results of dynamic ARDL simulations state a positive and significant relationship between 340 exports and carbon emissions in the short-run. China is one of the leading manufacturers and 341 exporter countries in the world. An increase of $1 \%$ in exports adds to environmental degradation 342 by $0.06 \%$ in the short run. Whereas in the long run, this relationship is negatively insignificant. An 343 increase of $1 \%$ in exports leads to reducing GHG emissions by $0.003 \%$. Trade has a bidirectional 
344 relationship with $\mathrm{CO}_{2}$ emissions (Mirza and Kanwal 2017; Chandia et al. 2018). In addition,

345 developed countries shift their $\mathrm{CO}_{2}$ emissions-related technologies to emerging economies (Khan

346 et al., 2019).

347 ECT is negatively significant (-0.1991), which states the speed of adjustment parameter aftershock.

348 ECT narrates that in one year, the rate of adjustment to the preceding equilibrium exists almost -

$34920 \%$. R-squared value presents that the independent variables of the study explained $88 \%$ variation

350 in $\mathrm{CO}_{2}$ emissions. For the ECT algorithm, this study utilized 5000 simulations for the variables

351 vector as recommended (Sarkodie et al., 2019). The P-value of the overall model is significant at

352 a $1 \%$ level. Root mean square error (RMSE) and F-statistics values of the model are also

353 favourable, which are 0.0091 and 19.24, respectively.

354 Table 7 shows the outcomes of dynamic ARDL simulations for sustainable environment taking 355 ecological footprint as a dependent variable. This indicates that market capitalization has an 356 insignificant relationship with ecological footprints for both the long and short-run. The 1\% 357 increase in market capitalization saves the environment by $0.01 \%$. Sharif et al. (2020) presented a 358 direct association of economic growth, while Godil et al. (2021) explored the negative relationship 359 of financial development with ecological footprints. In the short-run, economic growth outcomes 360 show a significant association with ecological footprints in China. The $1 \%$ increase in GDP affects $3610.38 \%$ of natural resources. In the long-run, economic growth shows a negative influence on 362 ecological footprints similar to (Sharif et al. 2020), while financial development leads to ignoring 363 the environment (Godil et al., 2021).

364 Moreover, the results show a significantly positive association between energy consumption and 365 ecological footprints in the short-run. An increase of $1 \%$ in energy consumption influences the 
expansion of environmental degradation by about $0.75 \%$. On the other hand, this relationship is negatively insignificant in the long-run. Sharif et al. (2020) examined the negatively significant relationship between the environment and renewable energy consumption. In addition, it is found that emerging countries of the world look keen to use traditional ways of energy production based on fossil fuels, irrespective of the environment, to fulfil their energy demand (Khan et al., 2019).

\section{[INSERT TABLE 6]}

The results of Table 7 display that between non-renewable energy consumption and ecological footprints, there is an insignificantly negative and positive association in the short and long-run, respectively. An escalation in non-renewable energy use leads to polluting the environment (Bhattacharya et al., 2017). Non-renewable energy consumption shows a positively significant effect on natural resources (Sharif et al. 2020). The results of urbanization represent insignificant relation between environmental degradation and urbanization. This affiliation is direct in the shortrun whereas inverse in the long-run. The coefficients show that the influence of urbanization is stronger in the long-run in China. Similarly, the results of dynamic ARDL simulations show that there exists a positive and insignificant connection between exports and ecological footprints. The $1 \%$ increase in exports causes to spoil the environment by $0.01 \%$ in the short-run while and $0.04 \%$ in the long-run. There is a bidirectional relationship between trade and environmental degradation (Shahzad et al., 2017; Chandia et al., 2018).

Besides, ECT is negatively significant (-0.7561). In this model, ECT narrates that the speed of adjustment to the preceding equilibrium is almost $76 \%$ in one year. R-squared value presents that the independent variables explain $-76 \%$ variation in ecological footprints. The P-value of the overall model is significant at 1\%. F-statistics and RMSE values are 8.31 and 0.0071 , respectively. 


\subsection{Graphs of dynamic ARDL simulations}

389

390

391

392

393

394

395

396

397

398

399

400

401

402

403

404

405

406

Fig. 3 presents positive and negative $10 \%$ change in market capitalization and its impact on carbon emissions in China for 1970-2017. A $10 \%$ increase in market capitalization saves the environment in a shorter period but deteriorates in the long-run, on the opposite, the decrease in urbanization assets a negative influence on environmental quality. Fig. 4 shows positive and negative $10 \%$ change in economic growth and its impact on carbon emissions in China for 1970-2017. The 10\% rise in GDP has positive and negative effects on carbon emissions in the long and short-run, respectively whilst decrease in GDP helps to save the environment in China.

[INSERT TABLE 7]

[INSERT FIGURE 3]

\section{[INSERT FIGURE 4]}

Fig. 5 reports positive and negative $10 \%$ change in energy use and its impact on carbon emissions. Escalation in energy consumption makes the environment deteriorate both in the long and shortrun. But, a 10\% decrease in energy use helps to support the environment. Fig. 6 shows positive and negative $10 \%$ change in non-renewable energy use and its impact on carbon emission in China for 1970-2017. It is shown that the rise in non-renewable energy use has a direct influence on carbon emissions in the short-run. Still, an inverse impact in the long-run as non-renewable sources save the environment. Moreover, a $10 \%$ decrease in non-renewable energy use supports the environment.

[INSERT FIGURE 5] 
409 Fig. 7 shows positive and negative $10 \%$ change in urbanization and its impact on carbon emissions

410 in China. The rise in urbanization has a positive influence on carbon emissions. On the other hand,

411 a 10\% decrease in urbanization helps to minimize environmental degradation in the short-run than

412 in the long-run. Fig. 8 reports positive and negative $10 \%$ change in exports of products and its

413 impact on carbon emissions in China over 1970-2017. A rise in exports has a direct effect on

414 carbon dioxide emissions. In contrast, a 10\% decrease in exports has an opposite influence on 415 carbon emissions.

\section{[INSERT FIGURE 7]}

[INSERT FIGURE 8]

418 Fig 9 indicates CUSUM (cumulative sum) and CUSUM squares graphs at a 5\% significance level.

419 These two graphs are utilized to know the reliability of the coefficient. Both the graphs represent 420 the upper and lower boundary lines, and between these limits, residual values are shown. These 421 residual values are between the boundaries and prove that the examined DARDL model is stable 422 and reliable at a 5\% significance level.

[INSERT FIGURE 9]

\section{5. Conclusion}

425 This study has sought to extend the extant literature on sustainable environmental, energy and 426 finance by applying a dynamic model to evaluate the effects of sustainable finance and other 427 economic factors on the environment in China using annual data from 1970 to 2017. The main 
428 findings are as follows. First, the results indicate that the study's variables are stationary at the first 429 order that leads to long-run cointegration and equilibrium. Second, empirical outcomes of this 430 study show that the novel measure of sustainable finance (market capitalization) exerts a negative 431 and positive influence on carbon emissions in the short- and long-run, respectively. Similarly, 432 these results in the short-run are robust with ecological footprints through which it is evident that 433 sustainable finance placed a reasonable cause to preserve the environment. In the long-run, on the 434 contrary, sustainable finance leads to observable degradation of the environment. This might be 435 due to the more use of non-renewable energy production sources in China. In the long run, other 436 sustainable economic factors, such as urbanization capture a positive impact on $\mathrm{CO}_{2}$ emissions, 437 while economic growth, energy use, and exports are worthy indicators to improve environmental 438 quality. Finally, these results have adverse effects in the short-run. Urbanization negatively 439 impacts the environment, while economic growth, energy consumption, and exports have a 440 positive impact on $\mathrm{CO}_{2}$ emissions in China.

441 Firstly, our findings will be of interest to investors, especially Chinese investors as they are 442 required to attain an optimal level of sustainable finance in order to achieve sustainable economic 443 growth. Second, since economic growth has a negative influence on GHG emissions, in the long444 run, it seems appropriate to work towards increasing GDP so that maximum economic growth 445 along with a sustainable environment can be accomplished in order to fulfil the target of net-zero $446 \mathrm{CO}_{2}$ emissions by 2060. Third, in the short-run, energy consumption adds to pollute the 447 environment by emitting more carbon emissions in China. It is pertinent, therefore, to replace the 448 conventional energy production techniques with renewable and sustainable energy consumption 449 methods. Hence, policymakers in China, as well as other leading CO2 emitters' economies, can 450 accomplish sustainable economic growth by providing subsidies on low carbon-emitting 
451 technologies and the availability of smart energy-efficient methods by imposing a ban on the use

452 of fossil fuels in order to improve the community's lifestyle. Future research can be applied with

453 the same set of variables in other leading GHG emitter countries following China, especially in

454 the Asian region or with additional sustainable factors to further explore sustainable growth by

455 persevering the environment.

456

\section{$457 \quad$ Ethical Approval}

458 Manuscript does not report on or involve the use of any animal or human data etc.

459 Consent to Participate

460 Authors have agreed for authorship, read and approved the manuscript, and given consent for 461 submission of the manuscript.

462 Consent to Publish

463 The authors have given consent for subsequent publication of the manuscript.

464 Funding

465 The funding does not apply to this research.

466 Competing Interests

467 The authors do not have any competing interests.

468 Availability of data and materials

469 The data will be provided upon a reasonable request to the corresponding author.

470 Authors Contributions

471 Rizwan Ali: Introduction, Writing results and discussion and Conclusion.

472 Mubeen Abdur Rehman: Abstract, Introduction and Literature Review.

473 Ramiz ur Rehman: Data analysis, Writing results and discussion, Methodology.

474 Collins G Ntim: Conceptualization, Data curation, Conclusion. 


\section{References}

Acquaye, A., Feng, K., Oppon, E., Salhi, S., Ibn-Mohammed, T., Genovese, A., \& Hubacek, K. (2017). Measuring the environmental sustainability performance of global supply chains: A multi-regional input-output analysis for carbon, sulfur oxide, and water footprints. Journal of environmental management, 187, 571-585.

Adom, P. K., Amuakwa-Mensah, F., \& Amuakwa-Mensah, S. (2020). Degree of financialization and energy efficiency in Sub-Saharan Africa: do institutions matter? Financial Innovation, 6(1), 1-22.

Ahmed, Z., Asghar, M. M., Malik, M. N., \& Nawaz, K. (2020). Moving towards a sustainable environment: the dynamic linkage between natural resources, human capital, urbanization, economic growth, and ecological footprint in China. Resources Policy, 67, 101677.

Akram, R., Majeed, M. T., Fareed, Z., Khalid, F., \& Ye, C. (2020). Asymmetric effects of energy efficiency and renewable energy on carbon emissions of BRICS economies: evidence from nonlinear panel autoregressive distributed lag model. Environmental Science and Pollution Research, 1-15.

Apergis, N., \& Garćia, C. (2019). Environmentalism in the EU-28 context: the impact of governance quality on environmental energy efficiency. Environmental Science and Pollution Research, 26(36), 37012-37025.

Baloch, M. A., Mahmood, N., \& Zhang, J. W. (2019). Effect of natural resources, renewable energy and economic development on $\mathrm{CO} 2$ emissions in BRICS countries. Science of the Total Environment, 678, 632-638.

Bekun FV, Emir F, Sarkodie SA (2019a) Another look at the relationship between energy consumption, carbon dioxide emissions and economic growth in South Africa. Sci Total Environ 655:759-765

Bekun FV, Alola AA, Sarkodie SA (2019b) Toward sustainable environment: nexus between CO2 emissions, resource rent, renewable and nonrenewable energy in 16-EU countries. Sci Total 
504

505

506

507

508

509

510

511

512

513

514

515

516

517

518

519

520

521

522

523

524

525

526

Bhattacharya, M., Churchill, S. A., \& Paramati, S. R. (2017). The dynamic impact of renewable energy and institutions on economic output and $\mathrm{CO} 2$ emissions across regions. Renewable Energy, 111, 157-167.

Bölük, G., \& Mert, M. (2014). Fossil \& renewable energy consumption, GHGs (greenhouse gases) and economic growth: Evidence from a panel of EU (European Union) countries. Energy, 74, 439-446.

Bougatef, K. (2017). Determinants of bank profitability in Tunisia: does corruption matter?. Journal of Money Laundering Control.

Chandia, K. E., Gul, I., Aziz, S., Sarwar, B., \& Zulfiqar, S. (2018). An analysis of the association among carbon dioxide emissions, energy consumption and economic performance: an econometric model. Carbon Management, 9(3), 227-241.

Charfeddine, L. (2017). The impact of energy consumption and economic development on ecological footprint and $\mathrm{CO} 2$ emissions: evidence from a Markov switching equilibrium correction model. Energy Economics, 65, 355-374.

Cho, J. S., Kim, T. H., \& Shin, Y. (2015). Quantile cointegration in the autoregressive distributed lag modeling framework. Journal of Econometrics, 188(1), 281-300.

Collins, D., \& Zheng, C. (2015). Managing the poverty-CO2 reductions paradox: the case of China and the EU. Organization \& Environment, 28(4), 355-373.

Destek, M. A., \& Sinha, A. (2020). Renewable, non-renewable energy consumption, economic growth, trade openness and ecological footprint: Evidence from organisation for economic co-operation and Development countries. Journal of Cleaner Production, 242, 118537.

Dogan, E., Taspinar, N., \& Gokmenoglu, K. K. (2019). Determinants of ecological footprint in MINT countries. Energy \& Environment, 30(6), 1065-1086. 
Duasa, J. (2007). Determinants of Malaysian trade balance: An ARDL bounds testing approach. Global Economic Review, 36(1), 89-102.

Engle, R. F., \& Granger, C. W. (1987). Co-integration and error correction: representation, estimation, and testing. Econometrica: Journal of the Econometric Society, 251-276.

Erdoğan, S. (2013). Econometric analysis of the impact of urbanization on CO2 emissions and energy use of Turkey.

Eren, B. M., Taspinar, N., \& Gokmenoglu, K. K. (2019). The impact of financial development and economic growth on renewable energy consumption: Empirical analysis of India. Science of the Total Environment, 663, 189-197.

Fakher, H. A. (2019). Investigating the determinant factors of environmental quality (based on ecological carbon footprint index). Environmental Science and Pollution Research, 26(10), 10276-10291.

Fareed, Z., Meo, M. S., Zulfiqar, B., Shahzad, F., \& Wang, N. (2018). Nexus of tourism, terrorism, and economic growth in Thailand: new evidence from asymmetric ARDL cointegration approach. Asia Pacific Journal of Tourism Research, 23(12), 1129-1141.

Godil, D. I., Ahmad, P., Ashraf, M. S., Sarwat, S., Sharif, A., Shabib-ul-Hasan, S., \& Jermsittiparsert, K. (2021). The step towards environmental mitigation in Pakistan: do transportation services, urbanization, and financial development matter? Environmental Science and Pollution Research, 1-13.

Grossman, G. M., \& Krueger, A. B. (1991). Environmental impacts of a North American freetrade agreement (No. w3914). National Bureau of economic research.

Hashmi, S. H., Fan, H., Fareed, Z., \& Shahzad, F. (2021). Asymmetric nexus between urban agglomerations and environmental pollution in top ten urban agglomerated countries using quantile methods. Environmental Science and Pollution Research, 28(11), 13404-13424.

Haug, A. A., \& Ucal, M. (2019). The role of trade and FDI for CO2 emissions in Turkey: Nonlinear 
relationships. Energy Economics, 81, 297-307.

553 Huang, M., \& Wang, B. (2016). Factors influencing CO2 emissions in China based on grey 554 relational analysis. Energy Sources, Part A: Recovery, Utilization, and Environmental 555 Effects, 38(4), 555-561.

556

557

558

559

560

561

562

563

564

565

566

567

568

569

570

571

572

573

574

575

576

Johansen, S., \& Juselius, K. (1990). Maximum likelihood estimation and inference on cointegration - with applications to the demand for money. Oxford Bulletin of Economics and Statistics, 52(2), 169-210.

Jordan, S., \& Philips, A. Q. (2018). Cointegration testing and dynamic simulations of autoregressive distributed lag models. The Stata Journal, 18(4), 902-923.

Kanjilal, K., \& Ghosh, S. (2013). Environmental Kuznets curve for India: Evidence from tests for cointegration with unknown structural breaks. Energy Policy, 56, 509-515.

Katircioğlu, S. T., \& Taşpinar, N. (2017). Testing the moderating role of financial development in an environmental Kuznets curve: empirical evidence from Turkey. Renewable and Sustainable Energy Reviews, 68, 572-586.

Khan, M. K., Teng, J. Z., Khan, M. I., \& Khan, M. O. (2019). Impact of globalization, economic factors and energy consumption on $\mathrm{CO} 2$ emissions in Pakistan. Science of the total environment, 688, 424-436.

Lahiani, A. (2020). Is financial development good for the environment? An asymmetric analysis with CO 2 emissions in China. Environmental Science and Pollution Research, 27(8), 79017909.

Lau, L. S., Choong, C. K., \& Eng, Y. K. (2014). Investigation of the environmental Kuznets curve for carbon emissions in Malaysia: do foreign direct investment and trade matter?. Energy Policy, 68, 490-497.

Mahmood, H., Maalel, N., \& Zarrad, O. (2019). Trade openness and CO2 emissions: Evidence from Tunisia. Sustainability 11 (12): 3295. 
Mirza, F. M., \& Kanwal, A. (2017). Energy consumption, carbon emissions and economic growth in Pakistan: Dynamic causality analysis. Renewable and Sustainable Energy Reviews, 72, 1233-1240.

Narayan, P. (2004). Reformulating critical values for the bounds F-statistics approach to cointegration: an application to the tourism demand model for Fiji (Vol. 2, No. 04). Australia: Monash University.

Nathaniel, S., \& Khan, S. A. R. (2020). The nexus between urbanization, renewable energy, trade, and ecological footprint in ASEAN countries. Journal of Cleaner Production, 272, 122709.

Nazir, M. R., Nazir, M. I., Hashmi, S. H., \& Fareed, Z. (2018). Financial development, income, trade, and urbanization on $\mathrm{CO} 2$ emissions: New evidence from Kyoto annex countries. Journal on Innovation and Sustainability RISUS, 9(3), 17-37.

Nosheen, M., Iqbal, J., \& Hassan, S. A. (2019). Economic growth, financial development, and trade in nexuses of CO 2 emissions for Southeast Asia. Environmental Science and Pollution Research, 26(36), 36274-36286.

Pata, U. K. (2018). Renewable energy consumption, urbanization, financial development, income and $\mathrm{CO} 2$ emissions in Turkey: testing EKC hypothesis with structural breaks. Journal of Cleaner Production, 187, 770-779.

Pesaran, M. H., Shin, Y., \& Smith, R. P. (1999). Pooled mean group estimation of dynamic heterogeneous panels. Journal of the American Statistical Association, 94(446), 621-634.

Pesaran, M. H., Shin, Y., \& Smith, R. J. (2001). Bounds testing approaches to the analysis of level relationships. Journal of applied econometrics, 16(3), 289-326.

Rahman, H. U., Ghazali, A., Bhatti, G. A., \& Khan, S. U. (2020). Role of economic growth, financial development, trade, energy and FDI in environmental Kuznets curve for Lithuania: evidence from ARDL bounds testing approach. Engineering Economics, 31(1), 39-49.

Rees, W. E. (1992). Ecological footprints and appropriated carrying capacity: what urban 
economics leaves out? Environment and urbanization, 4(2), 121-130.

603

604

605

606

607

608

609

610

611

612

613

614

615

616

617

618

619

620

621

622

623

624

625

626

Sadorsky, P. (2010). The impact of financial development on energy consumption in emerging economies. Energy Policy, 38(5), 2528-2535.

Sarkodie, S. A., \& Strezov, V. (2019). A review on environmental Kuznets curve hypothesis using bibliometric and meta-analysis. Science of the total environment, 649, 128-145.

Sarkodie, S. A., Strezov, V., Weldekidan, H., Asamoah, E. F., Owusu, P. A., \& Doyi, I. N. Y. (2019). Environmental sustainability assessment using dynamic autoregressive-distributed lag simulations-nexus between greenhouses gas emissions, biomass energy, food and economic growth. Science of the total environment, 668, 318-332

Shahbaz, M., Hye, Q. M. A., Tiwari, A. K., \& Leitão, N. C. (2013). Economic growth, energy consumption, financial development, international trade, and $\mathrm{CO} 2$ emissions in Indonesia. Renewable and Sustainable Energy Reviews, 25, 109-121.

Shahzad, S. J. H., Kumar, R. R., Zakaria, M., \& Hurr, M. (2017). Carbon emission, energy consumption, trade openness and financial development in Pakistan: a revisit. Renewable and Sustainable Energy Reviews, 70, 185-192.

Shahzad, U., Fareed, Z., Shahzad, F., \& Shahzad, K. (2021). Investigating the nexus between economic complexity, energy consumption and ecological footprint for the United States: New insights from quantile methods. Journal of Cleaner Production, 279, 123806.

Sharif, A., Baris-Tuzemen, O., Uzuner, G., Ozturk, I., \& Sinha, A. (2020). Revisiting the role of renewable and non-renewable energy consumption on Turkey's ecological footprint: Evidence from Quantile ARDL approach. Sustainable Cities and Society, 57, 102138.

Sharma, S. S. (2011). Determinants of carbon dioxide emissions: empirical evidence from 69 countries. Applied Energy, 88(1), 376-382.

Shin, Y., Yu, B., \& Greenwood-Nimmo, M. (2014). Modelling asymmetric cointegration and dynamic multipliers in a nonlinear ARDL framework. In Festschrift in Honor of Peter 
628

629

630

631

632

633

634

635

636

637

638

639

640

641

642

643

644

645

646

647

648

649

Toumi, S., \& Toumi, H. (2019). Asymmetric causality among renewable energy consumption, CO 2 emissions, and economic growth in KSA: evidence from a nonlinear ARDL model. Environmental Science and Pollution Research, 26(16), 16145-16156.

Ulucak, R., \& Lin, D. (2017). Persistence of policy shocks to Ecological Footprint of the USA. Ecological Indicators, 80, 337-343.

Wackernagel, M., \& Rees, W. E. (1997). Perceptual and structural barriers to investing in natural capital: Economics from an ecological footprint perspective. Ecological Economics, 20(1), 3-24.

Wang, S., Li, Q., Fang, C., \& Zhou, C. (2016a). The relationship between economic growth, energy consumption, and $\mathrm{CO} 2$ emissions: Empirical evidence from China. Science of the Total Environment, 542, 360-371.

Wang, Y., Chen, L., \& Kubota, J. (2016b). The relationship between urbanization, energy use and carbon emissions: evidence from a panel of Association of Southeast Asian Nations (ASEAN) countries. Journal of Cleaner Production, 112, 1368-1374.

WHO (2018) Who Global Ambient Air Quality Database (update 2018).

Zhang, B., Wang, B., \& Wang, Z. (2017). Role of renewable energy and non-renewable energy consumption on EKC: evidence from Pakistan. Journal of Cleaner Production, 156, 855-864.

Zhang, C., \& Lin, Y. (2012). Panel estimation for urbanization, energy consumption and CO2 emissions: A regional analysis in China. Energy Policy, 49, 488-498.

Zivot, E., \& Andrews, D. W. K. (2002). Further evidence on the great crash, the oil-price shock, and the unit-root hypothesis. Journal of Business \& economic statistics, 20(1), 25-44. 
Figures
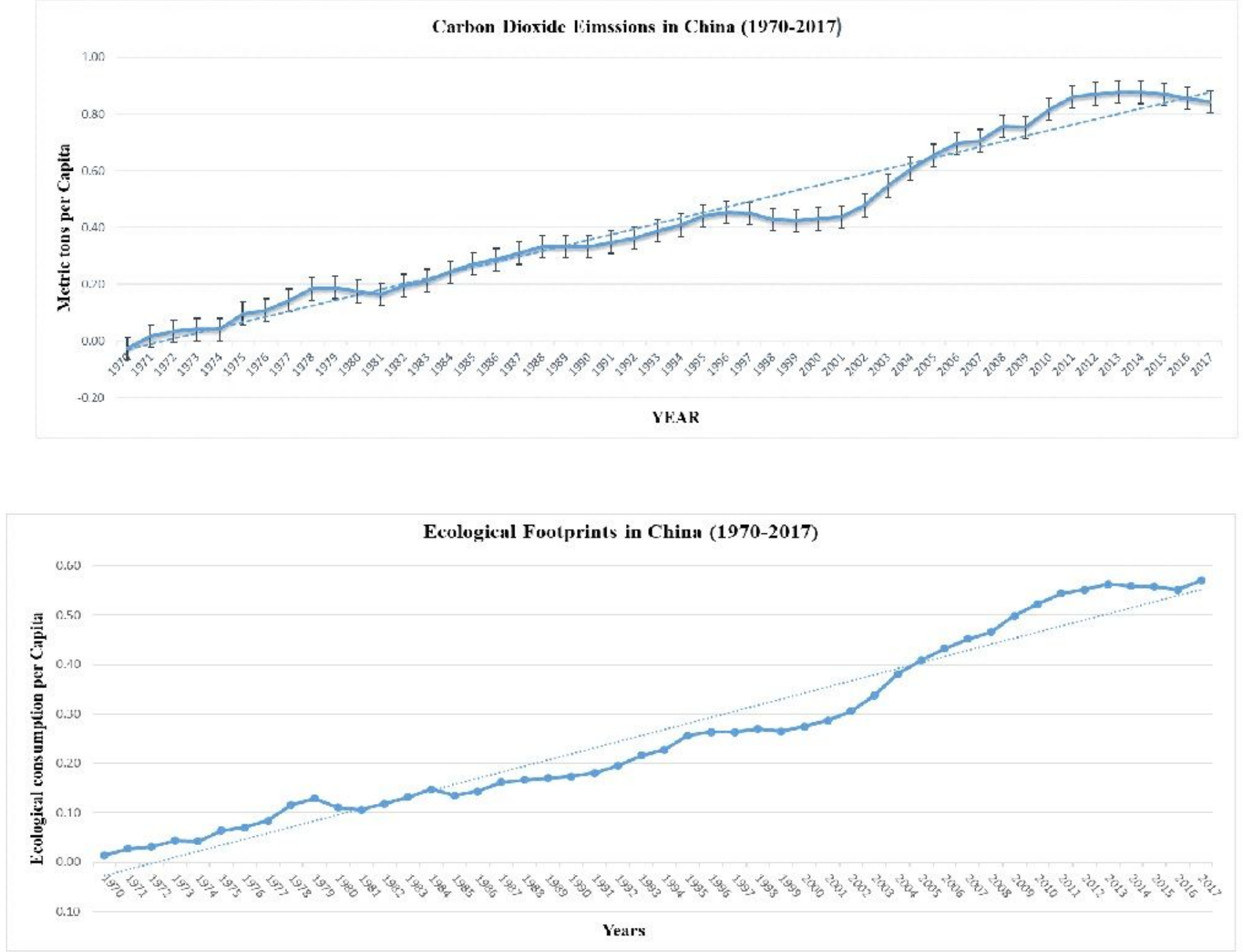

\section{Figure 1}

Representing the $\mathrm{CO}_{2}$ emissions and ecological footprints in China

Figure 2

Ecological Footprints in China over 1960-2017. 
Market capitalization and carbon dioxide emissions. The paired graphs represent $\pm 10 \%$ change in market capitalization and its impact on environmental degradation. Dots display ordinary forecasts, whereas the blue lines indicate a 95\% confidence interval, which decreases to $90 \%$ and $75 \%$ confidence interval as the line becomes thin in two stages.
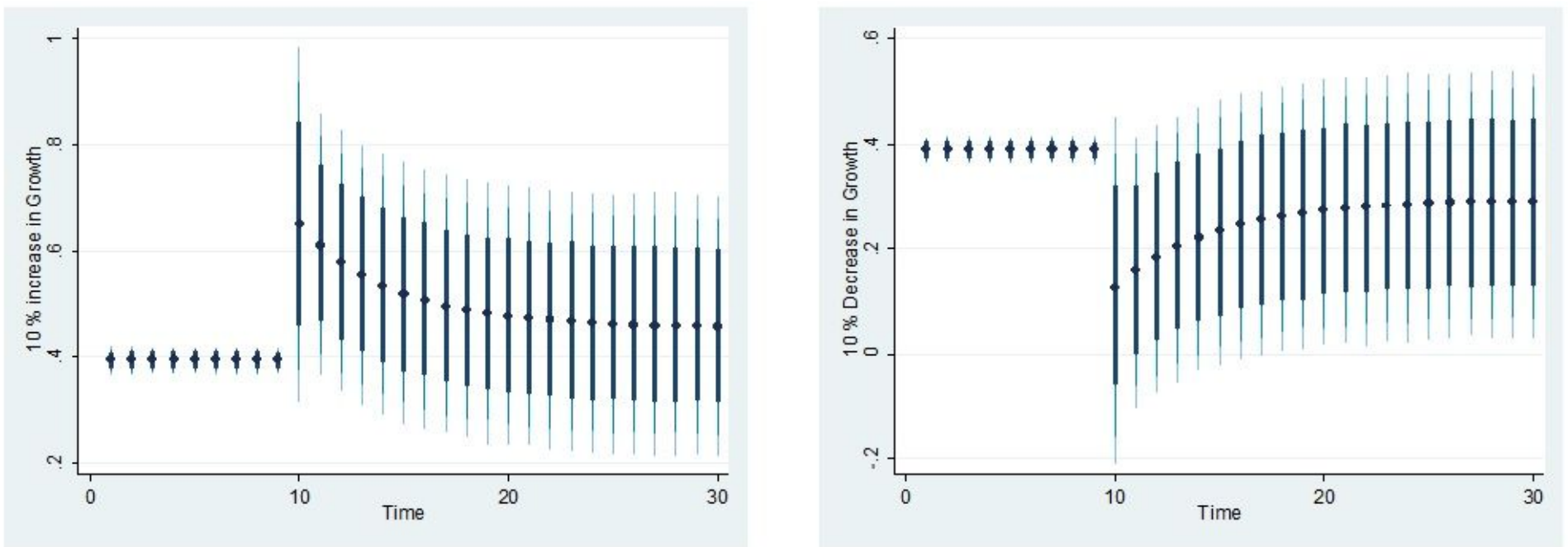

\section{Figure 4}

Economic growth and carbon dioxide emissions. The paired graphs represent $\pm 10 \%$ change in growth (GDP per capita) and its impact on environmental degradation. Dots display ordinary forecasts, whereas the blue lines indicate a 95\% confidence interval, which decreases to $90 \%$ and $75 \%$ confidence interval as the line becomes thin in two stages.

\section{Figure 5}

Energy use and carbon dioxide emissions. The paired graphs represent $\pm 10 \%$ change in energy use and its impact on environmental degradation. Dots display ordinary forecasts, whereas the blue lines indicate a 95\% confidence interval, which decreases to $90 \%$ and $75 \%$ confidence interval as the line becomes thin in two stages 

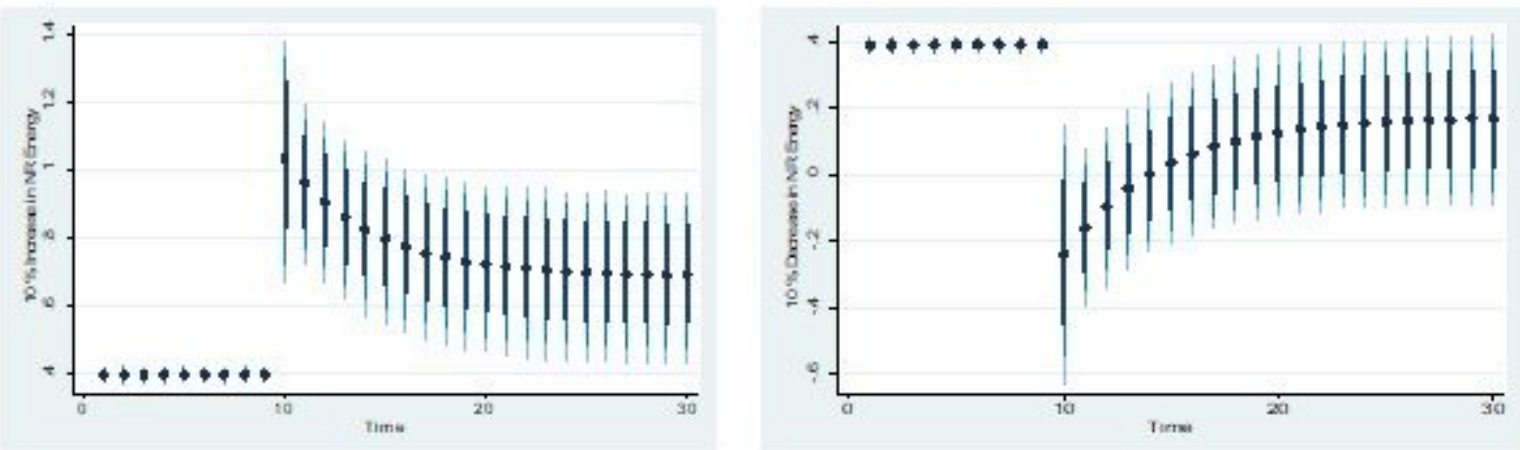

\section{Figure 6}

The above-shown graphs represent $\pm 10 \%$ in non-renewable energy consumption and its impact on carbon emissions. The Dots display an average forecast while the dark blue line indicates $95 \%$ confidence interval, which decreases to $90 \%$ and $75 \%$ confidence interval as the line becomes thin in two stages.
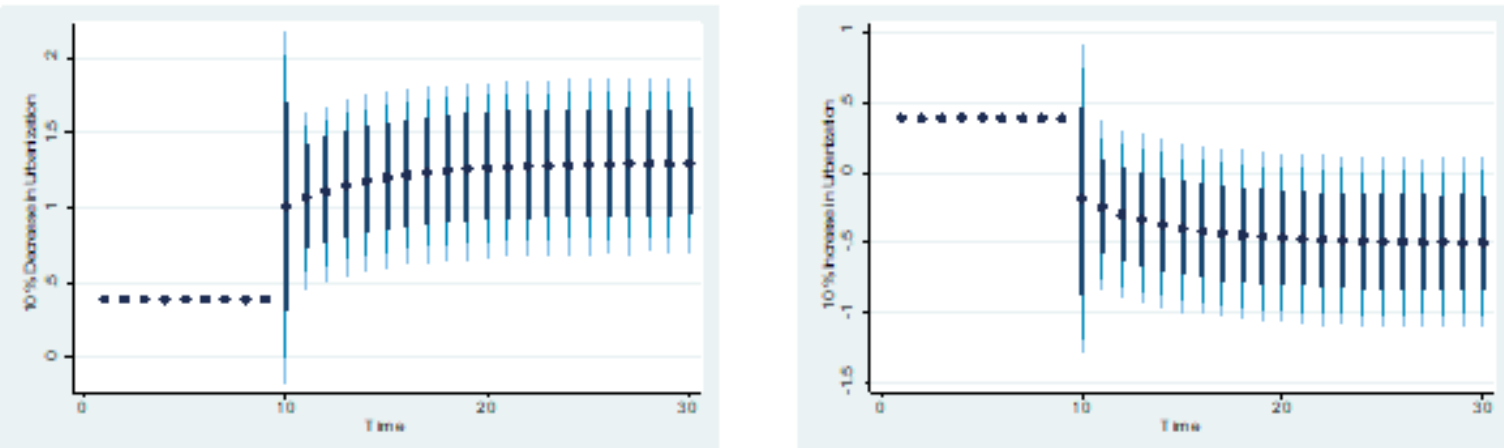

Figure 7

Urbanization and carbon dioxide emissions. The paired graphs represent $\pm 10 \%$ change in urbanization and its impact on environmental degradation. Dots display ordinary forecasts, whereas the blue lines indicate $95 \%$ confidence interval, which decreases to $90 \%$ and $75 \%$ confidence interval as the line becomes thin in two stages.

\section{Figure 8}

Exports and carbon dioxide emissions. The paired graphs represent $\pm 10 \%$ change in exports and its impact on environmental degradation. Dots display ordinary forecasts, whereas the blue lines indicate 
95\% confidence interval, which decreases to $90 \%$ and $75 \%$ confidence interval as the line becomes thin in two stages.
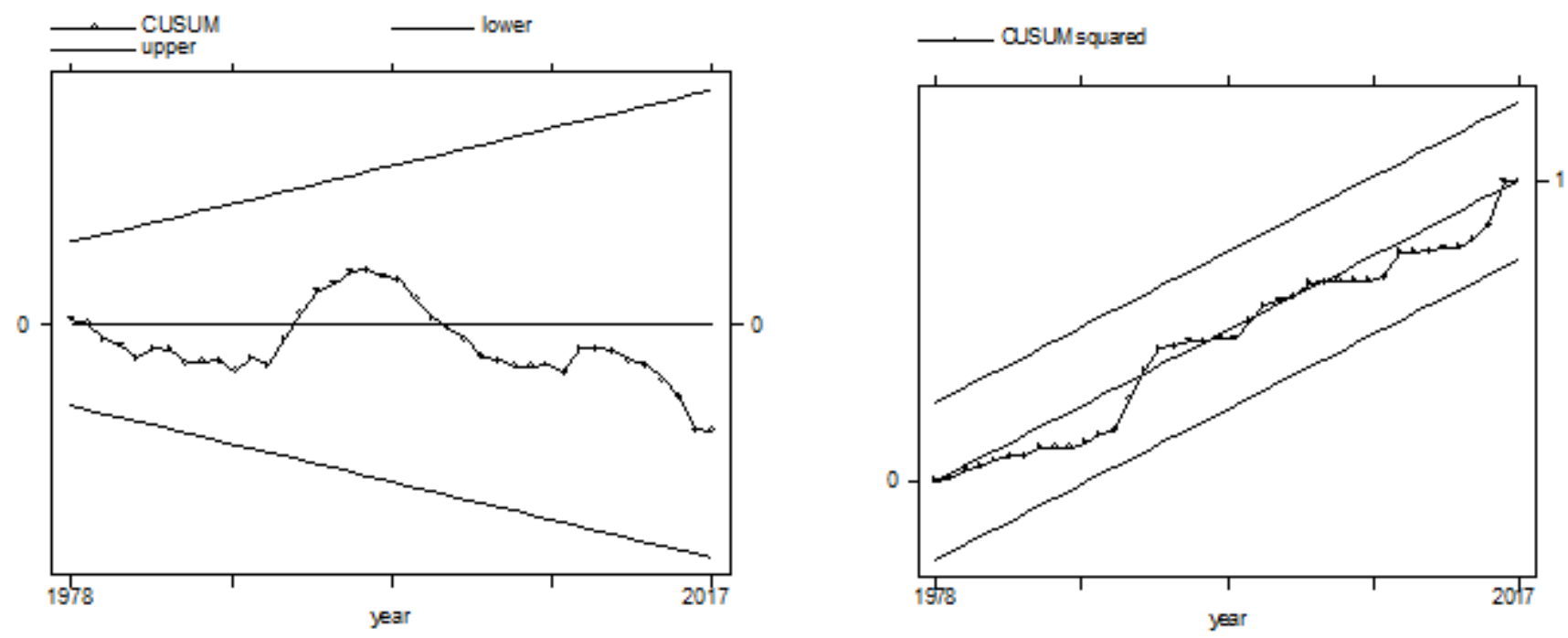

Figure 9

CUSUM and CUSUM square graphs indicate a 5\% significance level. Upper and lower dotted lines represent the upper and lower limits of stability.

\section{Supplementary Files}

This is a list of supplementary files associated with this preprint. Click to download.

- GraphicalAbstract.docx 